Article

\title{
Application of Photocatalysts and LED Light Sources in Drinking Water Treatment
}

\author{
Maryam Izadifard ${ }^{1}$, Gopal Achari ${ }^{2}$ and Cooper H. Langford ${ }^{1, *}$
}

1 Departments of Chemistry, University of Calgary, 2500 University Dr. NW, Calgary, AB, T2N 1N4, Canada; E-Mail: izadifam@ucalgary.ca

2 Department of Civil Engineering, University of Calgary, 2500 University Dr. NW, Calgary, AB, T2N 1N4, Canada; E-Mail: gachari@ucalgary.ca

* Author to whom correspondence should be addressed; E-Mail: chlangfo@ucalgary.ca;

Tel.: +1-403-220-3228; Fax: +1-403-289-9488.

Received: 15 June 2013; in revised form: 20 August 2013 / Accepted: 28 August 2013 /

Published: 12 September 2013

\begin{abstract}
This study investigates a cross-section of $\mathrm{TiO}_{2}$ compositions for which existing evidence suggests the prospect of improved performance compared to standard Degussa P25. In the context of a program aimed toward a $365 \mathrm{~nm}$ LED based photo-reactor, the question is whether a distinctly superior photocatalyst composition for drinking water treatment is now available that would shape design choices. An answer was sought by synthesizing several photocatalysts with reported high reactivity in some context in the literature, and by performing photocatalysts reactivity tests using common pollutants of water system including Natural Organic Matter (NOM) and Emerging Contaminants (ECs) from the pesticide and pharmaceutical classes. $365 \mathrm{~nm}$ Light Emitting Diodes (LEDs) were used as the irradiation source. Since LEDs are now available in the UV, we did not examine the $\mathrm{TiO}_{2}$ modifications that bring band gap excitation into the region beyond 400 $\mathrm{nm}$. The results suggest that the choice of the photocatalyst should be best made to fit the reactor design and photocatalyst mounting constraints such as mass transport, reactive surface, and light field. No photocatalyst composition overall, superior for all classes emerged.
\end{abstract}

Keywords: photocatalyst; Light Emitting Diodes; fulvic acids; emerging contaminants 


\section{Introduction}

There is lively current interest in the prospects for implementation of Advanced Oxidation Processes (AOPs) for water treatment [1,2]. AOPs refer to processes like electrochemical, ultrasound, $\mathrm{UV} / \mathrm{O}_{3}, \mathrm{UV} / \mathrm{H}_{2} \mathrm{O}_{2}$, Fenton and photo Fenton processes, photocatalysis, etc. The focus of this study is on moving towards $\mathrm{TiO}_{2}$ photocatalysts with UV- LED light sources. LED light sources, beyond being a reliable and continuous source (unlike solar), are inexpensive and promise high current-to-light conversion efficiency, with little heating (more efficient than many conventional mercury discharge lamps). DC operation could also be readily adapted to solar photovoltaic battery off-grid power.

Along with demonstrating UVA (as found in current LED light sources) this work is aimed at selecting among well characterized and readily prepared photocatalysts of reported high reactivity in at least one context (Table 1 in the Appendix lists some of the synthesized photocatalysts reported in the literature - mostly rare earth doped $\mathrm{TiO}_{2}$ - and the model compounds used for the reactivity test). The results and discussion section opens with an account of selection of candidate photocatalysts.

So far, UV LED light sources along with $\mathrm{TiO}_{2}$ photocatalysts (mostly Degussa P25) have been successfully used for degradation of dyes like Methylene Blue, Rhodamine B and Congo Red in aqueous medium [3-6]. Degradation of airborne 2-propanol, trichloroethylene, dimethyl sulfide and perchloroethylene has also been studied in gas phase [7-10]. Ghosh et al. in 2009 used visible LEDs $(436 \mathrm{~nm})$ for sensitized degradation of 4-chlolophenol (4-CP) using cumorine dye along with $\mathrm{TiO}_{2}$ nanofibers, tin-doped $\mathrm{TiO}_{2}$ nanofibers as well as Degussa P25 [11,12].

This work is a precursor to design a reactor for small and/or remote water systems. One typical requirement for the small systems is simplicity, with a minimum number of treatment steps. Photocatalysis with $\mathrm{TiO}_{2}$ is a broad gage treatment technique. Especially in the case of small systems, a single barrier approach is used and simple chlorination deals only with pathogens and creates a DBP problem. The broad applicability of UV photocatalysis offers hope for more comprehensive treatment. There is a growing literature on UVA-LED photocatalysis, but little of it has addressed environmental applications. Therefore, a contemporary statement of the problem faced by small systems would focus on three issues in the common order of priority: pathogens, disinfection by products (DPBs), and emerging micro-pollutants (arising from pesticides, pharmaceutical and personal care products). The first two are already being regulated and ECs may soon be regulated. Literature reviews document the broad spectrum capability of $\mathrm{TiO}_{2}$ photocatalysis to destroy microbes [13,14]. Thus, in this paper, representatives from the DBPs precursor Natural Organic Matter (Suwannee River Fulvic AcidsSRFA) and from ECs (4-CP \& sulfamethoxazole) were selected.

\section{Results and Discussion}

\subsection{Selection of Potential Photocatalyst Compositions and Reactivity Evaluation}

Selection of appropriate photocatalyst compositions requires one to consider factors influencing the performance of photocatalysts. These factors are subtle and complex, but in broad terms they can be divided into (a) issues of efficient delivery of the targets to the photocatalyst's surface and (b) target species reactivity on the surface. A key factor in delivery to the surface is adsorption on the surface, which relates to some specific interaction possibilities (e.g., chemisorption), point of zero charge and 
surface areas. Increasing the surface area of the photocatalysts results in increased both equilibrium and dynamic rates [15]. This calls for inclusion of preparations of nanotubes and wires or to mesoporous structures, all affording a high surface area. Another factor in reactivity on the surface is hole-electron recombination. It is argued that the success of P25 arises from the effect of the mixture of anatase and rutile phases, which reduces the recombination rate [16]. Recent research on nanoparticles of second oxides on $\mathrm{TiO}_{2}$ shows efficient separation of the hole and electron and delay of recombination. This even allows post-irradiation energy storage [17,18]. Existence of anatase and rutile phases, primary particle size and secondary particle size are other physical and structural properties, which affect the photocatalytic activities [19].

A review of literature suggested the following photocatalysts reported to have advantages such as outperforming Degussa P25 in at least one case: (a) mesoporous $\mathrm{TiO}_{2}$ and $\mathrm{TiO}_{2}$ nanofibers, which are reported to have large surface area [20,21]; (b) rare earths doped $\mathrm{TiO}_{2}$, to increases the separation efficiencies of electron and hole pairs and modifying the microstructure of the photocatalyst [22], and (c) photocatalysts with energy storage capability $\left(\mathrm{WO}_{3} / \mathrm{TiO}_{2}\right.$ and $\left.\mathrm{Ni}(\mathrm{OH})_{2} / \mathrm{TiO}_{2}\right)$. The electron storage capability of $\mathrm{WO}_{3} / \mathrm{TiO}_{2}$ extends lifetimes and as a consequence improves the interfacial transfer yield [18]. In contrast, surface coating with amorphous $\mathrm{Ni}(\mathrm{OH})_{2}$, which is a hole trap, can enhance the substrate adsorption as well [17]. All tests were also performed using Degussa P25 as a reference. In so far as the major factors in choice of a photocatalyst preparation can be captured by taking surface area as a surrogate for delivery of substrate to the surface and modeling charge separation by modification of the structure or creating opportunity for electron $\left(\mathrm{WO}_{3}\right)$ or hole $\left(\mathrm{Ni}(\mathrm{OH})_{2}\right)$ inter phase transfer, this set should provide a reasonable guide to the issues (since the reaction in case of $\mathrm{WO}_{3} / \mathrm{TiO}_{2}$ was efficient at $\mathrm{pH}$ around 3, this photocatalyst was not tested in this paper).

In the selection process, we also considered opportunities for immobilization, because there are considerable simplifications of reactor design if the photocatalyst is on a robust fixed bed. In this case, photocatalyst particle separation is not required. We have tested mesoporous $\mathrm{TiO}_{2}$, which could be representatives of mesosponge $\mathrm{TiO}_{2}$ prepared by anodization of titanium [5,23] and $\mathrm{TiO}_{2}$ nanofibers, which can also be obtained by anodization and could also represent nanofibers grown on a surface such as glass [24].

Since water may contain several classes of contaminants, the reactivity of the photocatalysts was tested on models of priority classes of water pollutants. Three main issues in drinking water treatment systems are pathogens, disinfection by products (DPBs), and emerging micro-pollutants, for which the potential of $\mathrm{TiO}_{2}$ photocatalysis (an alternate AOP) is especially promising. With respect to AOPs based on photocatalysis, an extensive literature on $\mathrm{TiO}_{2}$ demonstrates that oxidation with holes or hydroxyl radical equivalents on the $\mathrm{TiO}_{2}$ surface is an extremely powerful and versatile method of disinfection that has been recently reviewed $[25,26]$. Thus, we will not focus on testing a variety of catalysts over a variety of indicator organisms at this stage of UVA photocatalyst selection. The selection begins with the evaluation of candidate photocatalysts for degradation of the NOM model. NOM oxidation offers protection from DPB formation on the chlorination needed for the distribution system. Choices passing this test can then be evaluated for degradation of 4-CP as a challenging recalcitrant pesticide model and finally for sulfamethoxazole as an example of emerging pharmaceutical contaminants in water. This is consistent with Ryu and Choi's suggestion [27] to 
perform multiple reactivity tests for a specific photocatalyst, since a single activity test shows only a limited part of the variable activity.

It should be mentioned that for the reactivity tests, though the best loading for each photocatalyst was verified, the same loading of photocatalysts was used for the comparison purposes. This was not necessarily the optimized loading for each case, but reflects the expectation that a treatment system would not be altered for each contaminant. The $2.5 \mathrm{~g} / \mathrm{L}$ of photocatalysts used in this study was in the acceptable range for $\mathrm{P} 25, \mathrm{TiO}_{2}$ nanofibers and $\mathrm{Ni}(\mathrm{OH})_{2} / \mathrm{TiO}_{2}$ but $5 \mathrm{~g} / \mathrm{L}$ was the best loading for mesoporous $\mathrm{TiO}_{2}$. The UV irradiation source is $365 \mathrm{~nm}$ LEDs.

\subsection{Reduction of Natural Organic Matter (NOM) by UVA}

In North America, almost universally, small systems rely on chlorine disinfection and residual chlorine for distribution system protection. Many do not include coagulation or filtration or NOM removal. Thus, DBPs (trihalomethanes or THMs and haloacetic acids or HAAs) formation (increasingly regulated) stands out. DBPs are the result of reactions between NOM and chlorine. Removal of the NOM before chlorination is a desirable barrier. There are two photocatalytic options for degradation of NOMs: degradation by "self sensitization" under visible light irradiation or degradation under UV irradiation. A detailed and comprehensive study on NOM self sensitization using Degussa P25 has been pursued in this laboratory [28,29], which provides the proof of concept of applicability of this method for degradation of FAs and NOM, leading to inhibition of formation of DBPs. We report UV degradation of FAs in this paper since UV will be required for the other contaminants.

As it was mentioned in the introduction, SRFA in raw water model was used as the NOM model. Reactivity of the following photocatalysts was tested for degradation of SRFA (by following the characteristic fluorescence under $350 \mathrm{~nm}$ excitation as a function of time) in solution: $\mathrm{Nd}$ and $\mathrm{Eu}$ doped $\mathrm{TiO}_{2}$, Degussa $\mathrm{P} 25, \mathrm{TiO}_{2}$ nanofibers, $\mathrm{Ni}(\mathrm{OH})_{2} / \mathrm{TiO}_{2} \mathrm{WO}_{3} / \mathrm{TiO}_{2}$ and mesoporous $\mathrm{TiO}_{2}$. Upon band gap irradiation of the photocatalysts, electrons are excited to the conduction bands of $\mathrm{TiO}_{2}$ and leave highly oxidizing holes in valance band. In presence of NOM, these take part in a series of oxidative-reductive reactions, which includes electrons forming $\mathrm{O}_{2}{ }^{-}$and the powerful hole oxidant.

One of the critical factors in degradation of Fulvic Acids (FAs) is adsorption of FAs on the surface of the photocatalysts. Adsorption on the surface is strongly $\mathrm{pH}$ dependent with the optimum $\mathrm{pH}$ depending on surface properties, and the reactivity on the surface shows some $\mathrm{pH}$ dependence. Though the efficiency is higher at lower pHs, our goal here was to use the synthesized photocatalysts at natural water $\mathrm{pH}$. Figure 1 shows dark adsorption of FAs on the chosen catalysts at $\mathrm{pH}$ around 6.7. For the same loading of photocatalysts (not necessarily optimal), mesoporous $\mathrm{TiO}_{2}$ and $\mathrm{Ni}(\mathrm{OH})_{2} / \mathrm{TiO}_{2}$ are the best candidates. $\mathrm{P} 25, \mathrm{TiO}_{2}$ nanofibers and $\mathrm{Nd}$ doped $\mathrm{TiO}_{2}$ showed similar, lesser, adsorption efficiencies. The results for $\mathrm{WO}_{3} / \mathrm{TiO}_{2}$ are not reported here, because adsorption of $\mathrm{FAs}$ on the surface was not efficient, unless the $\mathrm{pH}$ was reduced to near 3 . The narrow band near $400 \mathrm{~nm}$ in this and all fluorescence spectra below is a water Raman band with constant intensity serving as an internal intensity standard. 
Figure 1. Dark adsorption of fulvic acids (FAs) (3 times diluted samples) on the surface of the selected photocatalysts $(2.5 \mathrm{~g} / \mathrm{L})$ at $\mathrm{pH}=6.7$, indicated by reduction in fluorescence intensity. Fluorescence spectra were recorded for $\lambda_{\text {excitation }}=350 \mathrm{~nm}$ ( 3 times diluted samples).

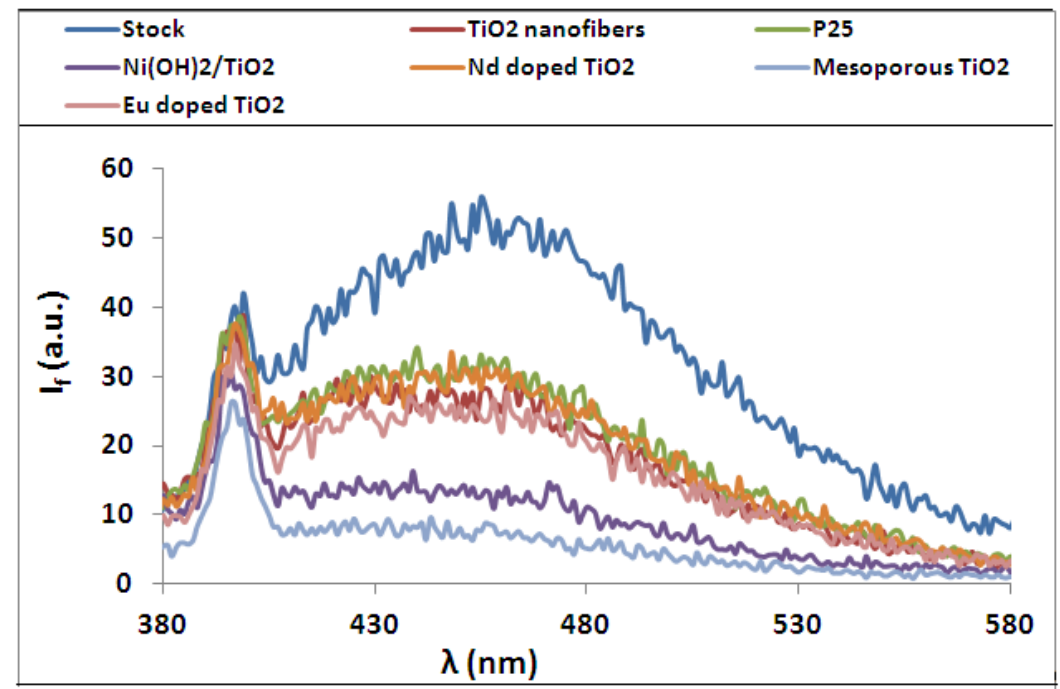

Figure 2 presents a typical result upon irradiation in $365 \mathrm{~nm}$ LED reactor using $\mathrm{TiO}_{2}$ nanofibres.

Figure 2. Degradation of FA (10 ppm) using $\mathrm{TiO}_{2}$ nanofibers $(2.5 \mathrm{~g} / \mathrm{L})$ in the $365 \mathrm{~nm} \mathrm{LED}$ reactor, the fluorescence spectra were recorded for $\lambda_{\text {excitation }}=350 \mathrm{~nm}$ at different irradiation times. Irradiation times are converted to required energy per volume in $(\mathrm{kJ} / \mathrm{L})$ for the corresponding removal of FA shown on the $Y$ axis.

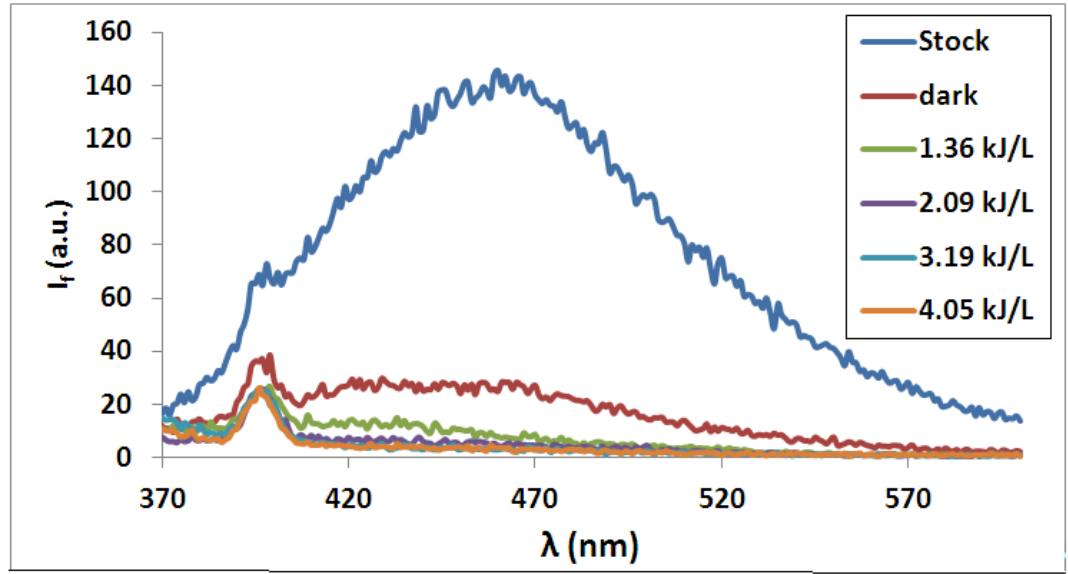


Figure 3. Final fluorescence spectra (3 times diluted samples) for $\lambda_{\text {excitation }}=350 \mathrm{~nm}$ of 10 ppm FA solutions using $2.5 \mathrm{~g} / \mathrm{L}$ of each photocatalyst after a light dose of $4.05 \mathrm{~kJ} / \mathrm{L}(1 \mathrm{~h})$ for runs in the $365 \mathrm{~nm}$ LED reactor (in case of Degussa P25, $2.25 \mathrm{~kJ} / \mathrm{L}(0.5 \mathrm{~h})$ was applied).

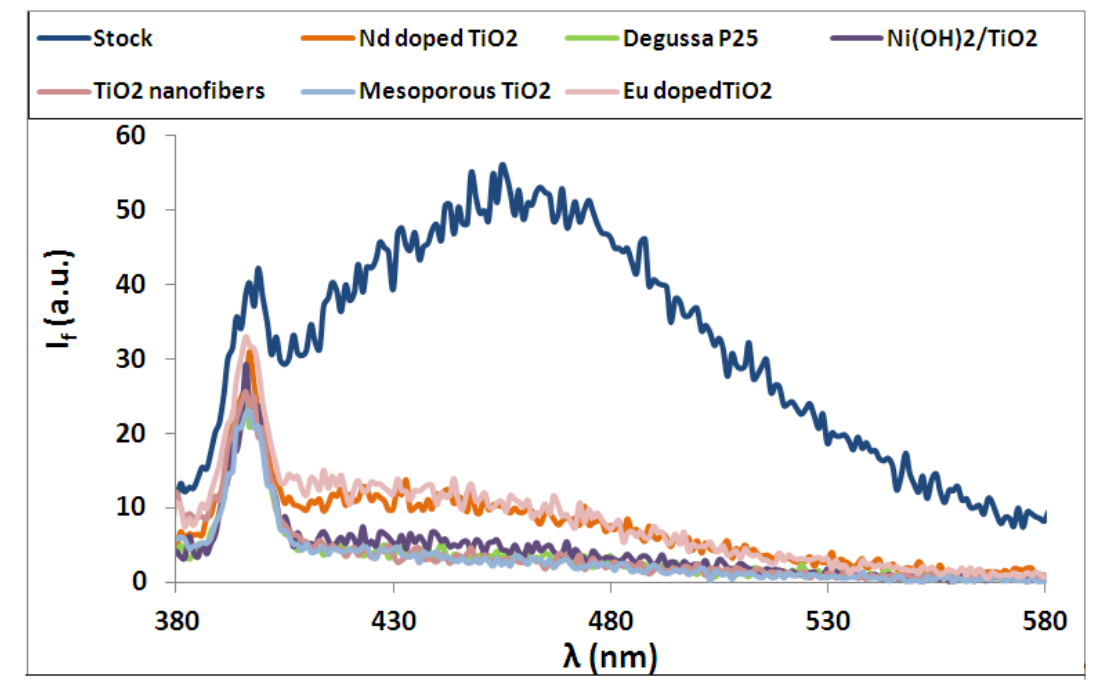

Figure 3 collects the final fluorescent spectra after a light dose of $4.05 \mathrm{~kJ} / \mathrm{L}(2.25 \mathrm{~kJ} / \mathrm{L}$ in case of Degussa P25) for a solution of $10 \mathrm{ppm}$ FA after each individual of the seven photocatalysts was used for irradiation in the $365 \mathrm{~nm}$ LED reactor. The final curves imply essentially complete reaction to non-fluorescent products, except in the cases of $\mathrm{Nd}$ and $\mathrm{Eu}$ doped $\mathrm{TiO}_{2}$, which show some remnant fluorescent photoproducts observed, even though the adsorption on the surface for rare earth doped $\mathrm{TiO}_{2}$ is similar to that for $\mathrm{P} 25$ and $\mathrm{TiO}_{2}$ nanofibers. It is possible that not all of the FA complex mixture's relevant components and oxidation intermediates are adsorbed on these surfaces. Also in the case of rare earth doped $\mathrm{TiO}_{2}$, particle sizes are so small that recorded absorption spectra of the photocatalysts were as if the slurry was a homogeneous solution. Below the critical size, surface recombination becomes dominant, reducing efficiency [30]. Alternatively, it could be related to electron trapping properties of the dopants, if the energy level is too low to transfer electron efficiently and rapidly to oxygen [30].

\subsection{Photocatalytic Degradation of Model Pesticide 4-CP under UVA Irradiation}

Literature suggests that 4-CP is among the most recalcitrant pesticide related structures with respect to oxidation [31]. Mesoporous $\mathrm{TiO}_{2}, \mathrm{TiO}_{2}$ nanofibers, $\mathrm{Ni}(\mathrm{OH})_{2} / \mathrm{TiO}_{2}$ as well as $\mathrm{P} 25$ were compared for degradation of 4-CP in $365 \mathrm{~nm}$ LED reactor. The results are shown in Figure 4A. The first point in all graphs is the based on the concentration after $30 \mathrm{~min}$ dark time. Adsorption of 4-CP on photocatalysts surfaces was determined to be negligible except for $\mathrm{Ni}(\mathrm{OH})_{2} / \mathrm{P} 25$, which was about $5 \%$. Nd doped $\mathrm{TiO}_{2}$, which is reported in the literature as the most efficient rare earth doped $\mathrm{TiO}_{2}$ photocatalysts [32,33], was also tested for degradation of 4-CP under similar circumstances. The reaction rate was very close to that of $\mathrm{TiO}_{2}$ nanofibers, but considering its poor performance on degradation of FA no more experiments were performed with this photocatalyst. In order to increase the efficiency of electron capture for the reactions, the photocatalysts were also tested under bubbling $\mathrm{O}_{2}$ for degradation of 4CP. $\mathrm{O}_{2}$ is the electron acceptor and, increase of concentration may reduce hole and electron 
recombination. The positive effect of $\mathrm{O}_{2}$ bubbling is shown in Figure 4B by shortening the overall degradation time. In both cases $\mathrm{P} 25$ was the most efficient photocatalyst followed by $\mathrm{Ni}(\mathrm{OH})_{2} / \mathrm{P} 25$, $\mathrm{TiO}_{2}$ nanofibers and mesoporous $\mathrm{TiO}_{2}$. Rate constants in both cases are listed in Table 2, where $k$ values are approximated by a pseudo first-order rate law.

Figure 4. Degradation of 4-CP (33 ppm) irradiated in $365 \mathrm{~nm}$ LED reactor using Degussa $\mathrm{P} 25, \mathrm{TiO}_{2}$ nanofibers, $\mathrm{Ni}(\mathrm{OH})_{2} / \mathrm{TiO}_{2}$ and mesoporous $\mathrm{TiO}_{2}$ without (A) and with $\mathrm{O}_{2}$ bubbling (B). Absorbance at $246 \mathrm{~nm}$ was monitored. Irradiation times are converted to required energy per volume in $(\mathrm{kJ} / \mathrm{L})$ for the corresponding removal of 4-CP shown on the $Y$ axis.

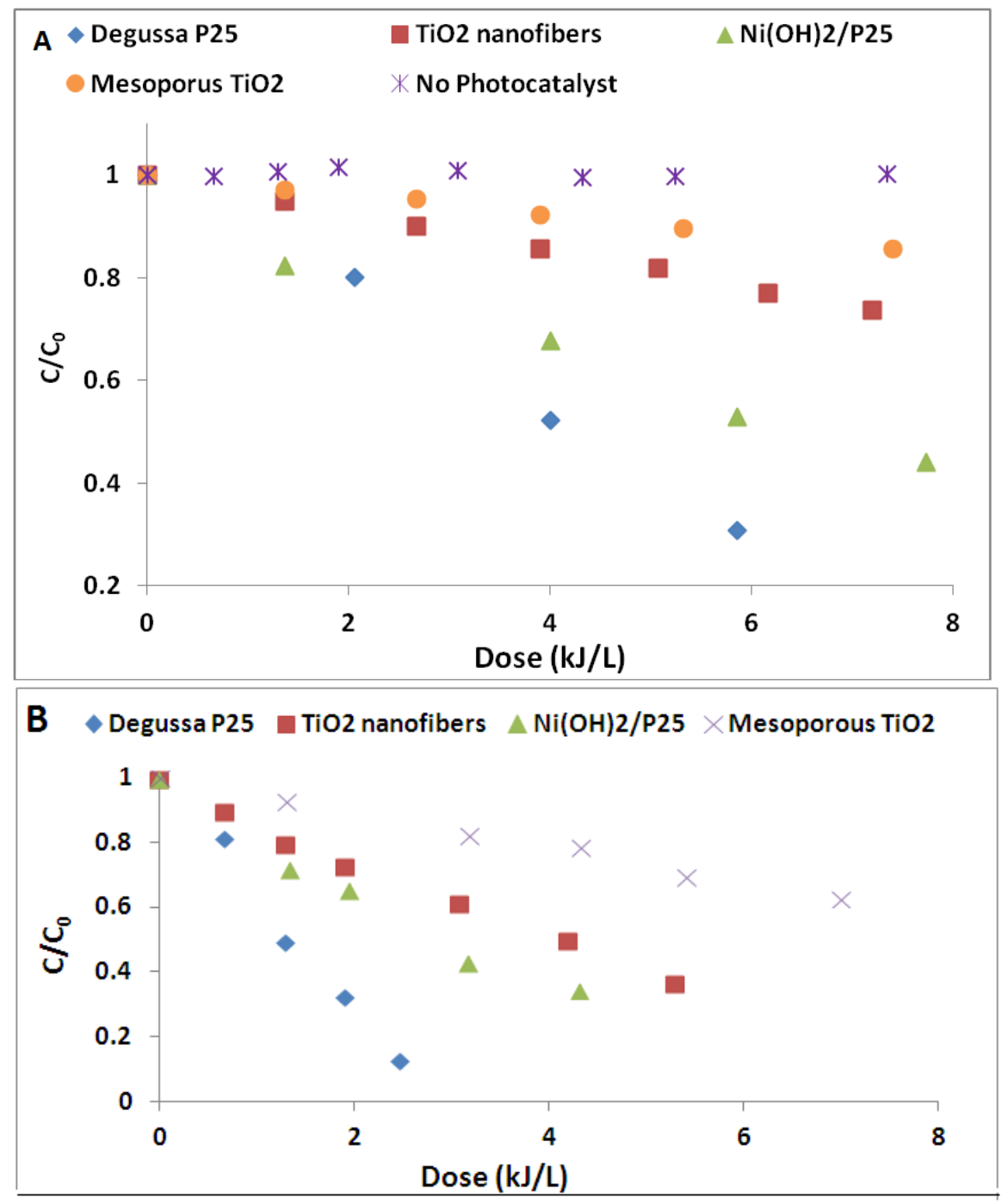

\subsection{Degradation of Sulfamethoxazole Using UVA $(365 \mathrm{~nm})$ Irradiation}

Degradation of sulfamethoxazole (SMX), which is one of the most commonly used antibiotics and one of the ECs [34], was also evaluated in the $365 \mathrm{~nm}$ LED reactor using $\mathrm{Ni}(\mathrm{OH})_{2} / \mathrm{TiO}_{2}, \mathrm{TiO}_{2}$ nanofibers, mesoporous $\mathrm{TiO}_{2}$ and $\mathrm{P} 25$. Figure 5 compares the results, where the first point corresponds to the normalized concentration after dark period. Adsorption of SMX on photocatalysts surfaces was determined to be negligible in all cases. Again the most efficient photocatalyst was P25 followed by 
$\mathrm{Ni}(\mathrm{OH})_{2} / \mathrm{P} 25$. $\mathrm{TiO}_{2}$ nanofibers and mesoporous $\mathrm{TiO}_{2}$ showed similar reactivity towards degradation of SMX. Rate constants listed in Table 1 are approximated by a pseudo first-order rate law.

Figure 5. Degradation of SMX (33 ppm) irradiated in $365 \mathrm{~nm}$ LED reactor using Degussa $\mathrm{P} 25, \mathrm{TiO}_{2}$ nanofibers and $\mathrm{Ni}(\mathrm{OH})_{2} / \mathrm{TiO}_{2}$. Absorbance at $266 \mathrm{~nm}$ was monitored. Irradiation times are converted to required energy per volume in $(\mathrm{kJ} / \mathrm{L})$ for the corresponding removal of SMX shown on the $Y$ axis.

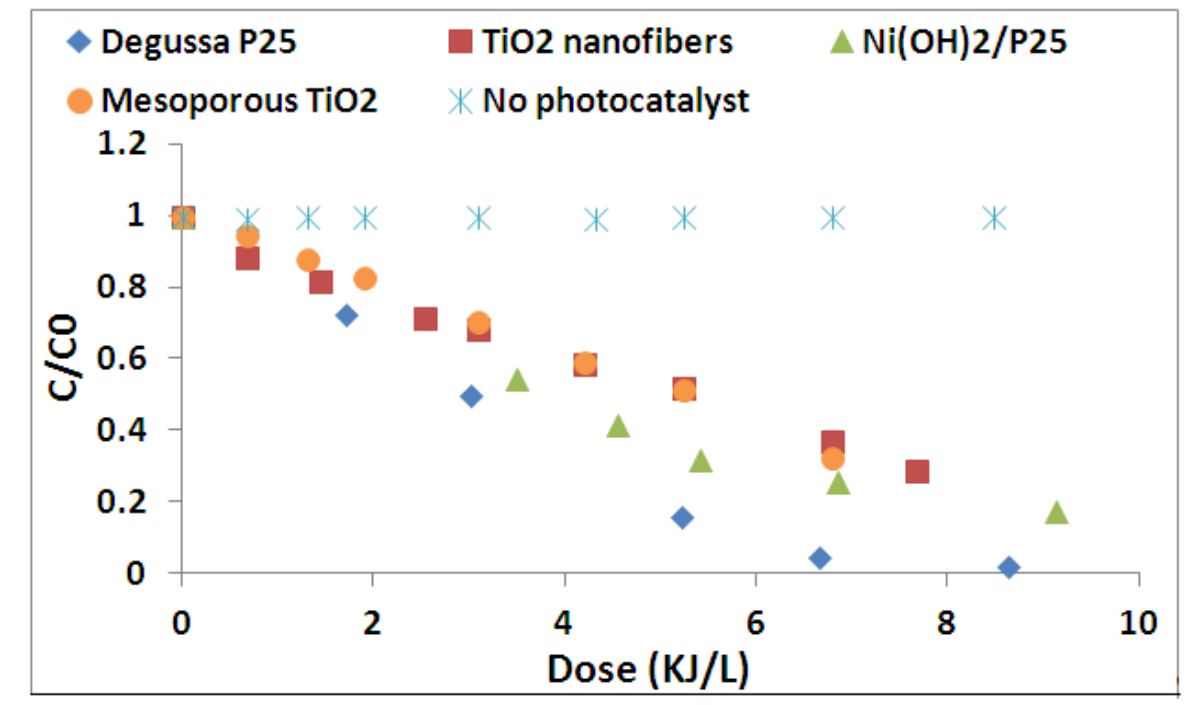

Introducing a superior photocatalyst requires that a given candidate exhibits higher levels of photocatalytic activity for several reactions with different reaction conditions. P25 was the most efficient photocatalyst for degradation of the candidate pollutant at $\mathrm{pH}$ 6-7 (balanced properties of P25: surface are of $50 \mathrm{~m}^{2} \mathrm{~g}^{-1}$, primary particle size of $30 \mathrm{~nm}$ and combination of anatase and rutile structures makes P25 one of the best photocatalysts known up to date [19]) but for a real water sample with $\mathrm{pH}$ of $8, \mathrm{Ni}(\mathrm{OH})_{2} / \mathrm{P} 25$ was more efficient than $\mathrm{P} 25$ in degrading FAs.

Table 1. Pseudo first order rate constants and $R^{2}$ for 4-CP (with and without $\mathrm{O}_{2}$ bubbling) and SMX.

\begin{tabular}{ccccc}
\hline \multirow{2}{*}{ Compound } & \multicolumn{4}{c}{ Photocatalyst } \\
\cline { 2 - 5 } & Degussa P25 & $\mathbf{N i}(\mathbf{O H})_{2} / \mathbf{P 2 5}$ & $\mathbf{T i O}_{2}$ nanofibers & Mesoporous $\mathbf{T i O}_{2}$ \\
\hline \multirow{2}{*}{$4-\mathrm{CP}$} & $k=0.0132 \mathrm{~min}^{-1}$ & $k=0.0066 \mathrm{~min}^{-1}$ & $k=0.0026 \mathrm{~min}^{-1}$ & $k=0.0013 \mathrm{~min}^{-1}$ \\
& $R^{2}=0.9702$ & $R^{2}=0.9924$ & $R^{2}=0.9994$ & $R^{2}=0.9968$ \\
$4-\mathrm{CP}, \mathrm{O}_{2}$ & $k=0.0503 \mathrm{~min}^{-1}$ & $k=0.0156 \mathrm{~min}^{-1}$ & $k=0.0106 \mathrm{~min}^{-1}$ & $k=0.0039 \mathrm{~min}^{-1}$ \\
& $\mathrm{R}^{2}=0.9425$ & $\mathrm{R}^{2}=0.9900$ & $R^{2}=0.9929$ & $R^{2}=0.9911$ \\
$\mathrm{SMX}$ & $k=0.0283 \mathrm{~min}^{-1}$ & $k=0.0119 \mathrm{~min}^{-1}$ & $k=0.0083 \mathrm{~min}^{-1}$ & $k=0.0089 \mathrm{~min}^{-1}$ \\
& $R^{2}=0.9739$ & $R^{2}=0.9886$ & $R^{2}=0.9850$ & $R^{2}=0.9727$ \\
\hline
\end{tabular}




\subsection{Choosing Appropriate Photocatalysts for Water Treatment Purposes}

The first step for photocatalytic treatment of water is to define characteristics of the water to be treated in terms of water composition and $\mathrm{pH}$. Normally we are faced with three basic types of source water: ground water, ground water affected by surface water (GUDI) and surface water. NOM is present in surface water but rarely in ground water unless it is contaminated from surface water. So based on the presence or absence of NOM (FAs as representatives of humic substances) the following options (Scheme 1) are available:

Scheme 1. Photocatalytic degradation of water pollutants and side reactions in presence or absence of NOM under UV or Visible irradiation. * Passive NOM sensitization is the case, where $\mathrm{TiO}_{2}$ is not directly excited by UV light. NOM absorb visible light to start the reaction.

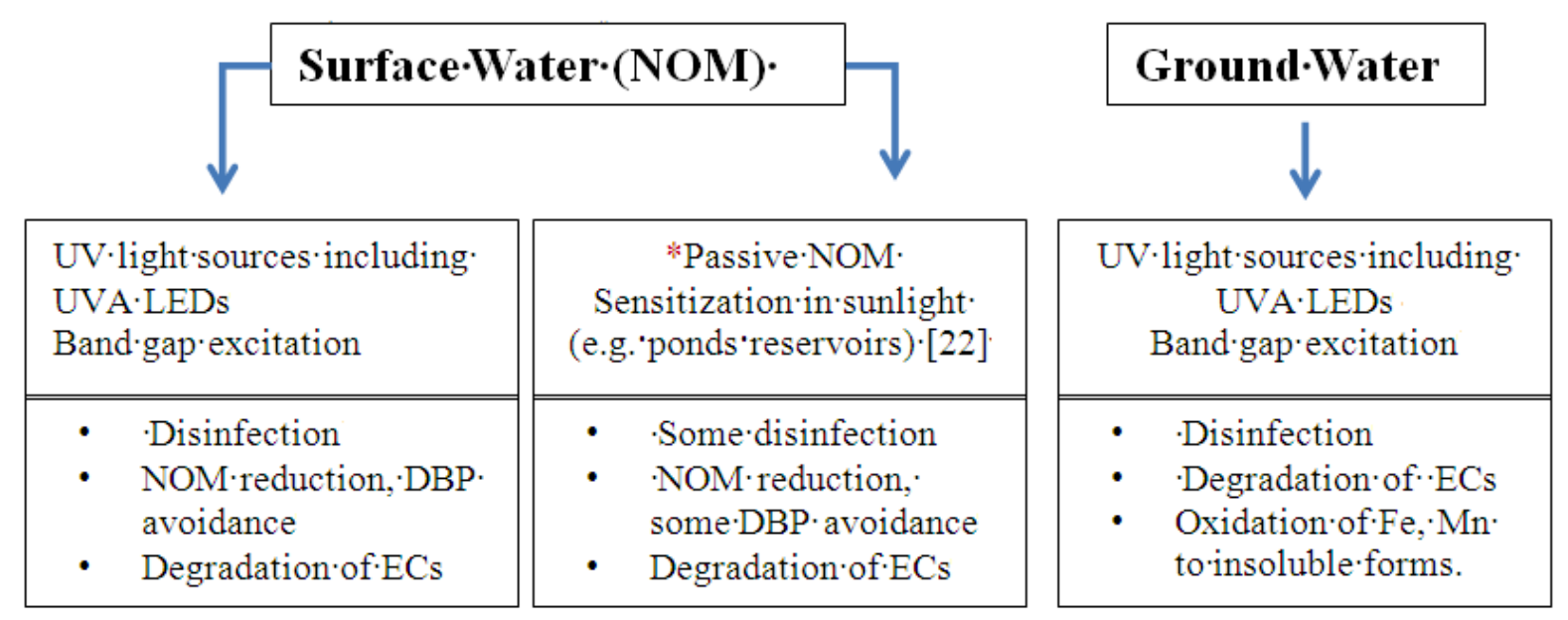

Degradation of ECs has been shown to be efficient when UV light sources are used. FAsphotosensitized degradation of ECs was also verified for degradation of 4-CP and it was efficient [29]. However, the NOM sensitized processes will vary greatly with the NOM composition and concentration.

Reviewing the reactivity tests performed using candidate photocatalysts, P25 was the most effective for degradation of 4-CP and SMX. If FAs (NOM) are present $\mathrm{Ni}(\mathrm{OH})_{2} / \mathrm{P} 25$ and mesoporous $\mathrm{TiO}_{2}$ are specifically good because of the very efficient adsorption of FAs $(\mathrm{NOM})$ on the surface. $\mathrm{Ni}(\mathrm{OH})_{2} / \mathrm{P} 25$ has been shown to be applicable at high pHs (around 8), where P25 is not efficient. Another advantage of this photocatalyst is, its easy separation compared to other photocatalyst. If a slurry is to be made using mixed photocatalysts (e.g., $\mathrm{Ni}(\mathrm{OH})_{2} / \mathrm{TiO}_{2}$ and P25) then one can take advantage of both photocatalysts. $\mathrm{TiO}_{2}$ nanofibers and mesoporous $\mathrm{TiO}_{2}$ are interesting candidates if a fixed bed reactor is to be used. There are different reported methods for growing $\mathrm{TiO}_{2}$ nanofibers on a surface [24] or to form mesoporous structure on a surface. An example is mesosponge $\mathrm{TiO}_{2}$ formed on $\mathrm{Ti}$ foil surface by anodization [23]. However, what is perhaps the most interesting conclusion is that despite the fact that the present results illustrate the need to compare photocatalysts by exploring a range of substrates [27], differences seen here are in the main not large and there will be little incentive to develop reactors with a photocatalyst choice dedicated to a single target substrate. 


\section{Materials and Methods}

\subsection{Materials}

The following chemicals were used in the experiments: europium (III) oxide $(99.9 \%)$ provided by REaction/Alfa Aesar (Ward Hill, MA, USA); neodymium (III) oxide (99.9\%) ; phosphotungstic acid (reagent grade) and nickel(II) nitrate hexahydrate (99.999\%) supplied by Sigma-Aldrich (St. Louis, MO, USA); Sulfamethoxazole by Fluka (St. Louis, MO, USA); Pluronic P-123 (a triblock copolymer: Poly(ethylene glycol)-block-poly(propylene glycol)-block-poly(ethylene glycol) by Sigma- Aldrich (St. Louis, MO, USA); isopropyl alcohol (99.99\%) by EMD (OmniSolv) (Gibbstown, NJ, USA); 4-chlorophenol by Aldrich and Suwannee river fulvic acid (a reference sample widely studied) from the International Humic Substance Society (IHSS) (St. Paul, MN, USA). Distilled deionized water was used as required in the experiments.

\subsection{Preparation of the Photocatalysts}

$\mathrm{TiO}_{2}$ nanofiber, which was kindly provided by Ghosh et al. [12], was prepared by the following procedure outlined by Sui et al., in which a mixture of heptane, acetic acid and titanium isopropoxide was heated to $60{ }^{\circ} \mathrm{C}$ until a gel was formed [20]. The gel was aged for 5 days, then dried at $80{ }^{\circ} \mathrm{C}$ and finally calcined at $400{ }^{\circ} \mathrm{C}$ for $2 \mathrm{~h}$.

A sol gel method described by $\mathrm{Xu}$ et al. was used to prepare the Eu and Nd doped photocatalysts [22]. Diluted titanium isopropoxide with isopropanol was added to the aqueous solution of Eu or $\mathrm{Nd}$ oxides with $\mathrm{pH}$ of 1.5 . The mixture was kept refluxing at $75{ }^{\circ} \mathrm{C}$ for $24 \mathrm{~h}$ and then the precipitate was dried at $60{ }^{\circ} \mathrm{C}$. $\mathrm{Ni}(\mathrm{OH})_{2}$ cluster-modified $\mathrm{TiO}_{2}\left(\mathrm{Ni}(\mathrm{OH})_{2} / \mathrm{TiO}_{2}\right.$ nanocomposite $)$ was fabricated using a precipitation method presented by $\mathrm{Yu}$ et al. using Degussa $\mathrm{P} 25$ as support and $\mathrm{Ni}\left(\mathrm{NO}_{3}\right)_{2}$ as precursor. Degussa P25 was dispersed in $1.0 \mathrm{M} \mathrm{NaOH}$ aqueous solution, to which was added $\mathrm{Ni}\left(\mathrm{NO}_{3}\right)_{2}$ aqueous solution. The mixed solutions were stirred for $24 \mathrm{~h}$ at room temperature. After that, the precipitates were collected and washed with distilled water and alcohol respectively and dried at $80{ }^{\circ} \mathrm{C}$ for $24 \mathrm{~h}$ [17]. $\mathrm{WO}_{3} / \mathrm{TiO}_{2}$ nanohybrid was also prepared by a sol gel method with titanium isopropoxide and phosphotungstic acid $\left(\mathrm{H}_{3} \mathrm{PW}_{12} \mathrm{O}_{40}\right)$ as precursors. Titanium isopropoxide dissolved in isopropanol was added to a solution of $\mathrm{H}_{3} \mathrm{PW}_{12} \mathrm{O}_{40}$ deionized water. The mixture was aged for $2 \mathrm{~h}$, the gel was dried at $100{ }^{\circ} \mathrm{C}$ and sintered at $500{ }^{\circ} \mathrm{C}$ for $5 \mathrm{~h}$. The powder was washed thoroughly with water and then dried at $80{ }^{\circ} \mathrm{C}[18]$.

Finally mesoporous $\mathrm{TiO}_{2}$ was prepared by a method suggested by Calleja et al.: Pluronic P-123 was first dissolved in a mixture of 2-propanol and $\mathrm{HCl}$ in water [21]. The resulting solution was stirred for $4 \mathrm{~h}$ and then it was added to a solution of titanium isopropoxide and 2-propanol under vigorous stirring at $40{ }^{\circ} \mathrm{C}$, obtained sol was kept under stirring until a gel appeared (molar ratio $\mathrm{H}_{2} \mathrm{O} / \mathrm{Ti}=6$ and grams of P-123 per $0.01 \mathrm{~mol}$ of $\left.\mathrm{Ti}_{\mathrm{i}}=1\right)$. The gel was aged at $40{ }^{\circ} \mathrm{C}$ and dried under ambient conditions. Finally, to extract the surfactant, the solid product was refluxed with ethanol for $24 \mathrm{~h}$.

Table 2 lists the physical properties of the synthesized photocatalysts reported in the original papers. It should be noted that the band gap for the synthesized photocatalyst is at least 3.2, which is the intrinsic band gap of anatase. In contrast to all of the others, in case of Eu and $\mathrm{Nd}$ doped $\mathrm{TiO}_{2}$, there is a shift to lower energies (longer wavelengths), which is not fully characterized. 
Table 2. Physical properties of the synthesized photocatalysts.

\begin{tabular}{|c|c|c|c|}
\hline Photocatalyst & Crystalline structure & Average particle size (nm) & composition \\
\hline $\mathrm{TiO}_{2}$ nanofibers [20] & Anatase & 13 & - \\
\hline $\mathrm{Ni}(\mathrm{OH})_{2} / \mathrm{TiO}_{2}[17]$ & Anatase and Rutile & 24 (Anatase), 46 (Rutile) & $\begin{array}{c}\mathrm{Ni}(\mathrm{OH}) / \mathrm{Ni}(\mathrm{OH})_{2}^{+} \\
\mathrm{P} 25=0.1\end{array}$ \\
\hline $\mathrm{WO}_{3} / \mathrm{TiO}_{2}[18]$ & Anatase & $9.5-10$ & $\mathrm{~W} / \mathrm{Ti}($ mole ratio $)=0.04$ \\
\hline Mesoporous $\mathrm{TiO}_{2}[21]$ & Anatase & 2.8 (pore size) & - \\
\hline Eu doped $\mathrm{TiO}_{2}[22]$ & $\begin{array}{c}\text { Anatase with a little } \\
\text { brookite }\end{array}$ & 5.5 & $\begin{array}{c}\mathrm{Eu}_{2} \mathrm{O}_{3} / \mathrm{Ti}(\mathrm{OiPr})_{4}(\text { mole } \\
\text { ratio })=0.01\end{array}$ \\
\hline
\end{tabular}

Successful preparation of the chosen photocatalysts was selectively confirmed by SEM/EDS: Scanning Electron Microscopy with X-ray microanalysis (Figure A1 in the Appendix). An extensive set of figures is not included here since the cited literature was confirmed.

\subsection{Reactivity Evaluation}

Suwannee river fulvic acids (FAs), representing NOM; 4-CP representing pesticide type molecules, and Sulfamethoxazole (SMX) representing pharmaceuticals, were chosen as model compounds to test the reactivity of the synthesized photocatalysts. 4-CP solution and SMX (33 ppm) were prepared by dissolving 4-CP or SMX in Milli- $\mathrm{Q}$ water without changing the $\mathrm{pH}$. FAs samples were model "natural water samples", which were prepared using the following recipe: $0.020 \mathrm{~g}$. of Suwannee river FA, $0.117 \mathrm{~g}$ of calcium chloride and $0.181 \mathrm{~g}$ of sodium bicarbonate was added to $2 \mathrm{~L}$ of boiling Milli-Q water. The $\mathrm{pH}$ of the solution was then adjusted between 7.1-7.3. The solution had about $10 \mathrm{ppm}$ of FA. Reactivity tests were performed using $0.25 \%(w / v-2.5 \mathrm{~g} / \mathrm{L})$ photocatalysts slurries (see discussion for more detail). The slurries were agitated in dark for $30 \mathrm{~min}$ using a magnetic stirrer prior to irradiation.

The solutions were then subjected to irradiation for appropriate periods in a compact circular bench scale reactor equipped with $365 \mathrm{~nm}$ LED lamps [35]. The inside diameter and depth of the reactor are 9 and $7 \mathrm{~cm}$ respectively and it is equipped with 90 LED $3 \mathrm{~mW}$ output lamps (NSHU5518), which are evenly distributed in 15 rows (Figure A2 in the Appendix). The number of photons absorbed by the solutions was determined by chemical actinometry using potassium ferrioxalate [36]. Incident photon flux, measured under exactly the same conditions as in the photocatalytic experiments, was evaluated to be $4.3 \pm 0.2 \times 10^{16}$ photos/s for the LED reactor. This light intensity was used to calculate energy dosage. Energy dosage is calculated using the following equation:

$$
E=I \times t \times h c 1000 \lambda
$$

where $E$ is energy dosage delivered into the sample (in $\mathrm{kJ}$ ), $I$ is light intensity (photons/s), $t$ is irradiation time(s), $h$ is Planck's constant (Js), $c$ is velocity of light in vacuum $(\mathrm{m} / \mathrm{s})$ and $\lambda$ is wavelength of photon in $\mathrm{m}$.

At predetermined time intervals, slurry samples were withdrawn, centrifuged and filtered through $0.45 \mu$ filters. For the nanoparticles, addition of $\mathrm{NaOH}$ made the separation of the photocatalyst much easier and faster. In case of using $\mathrm{Ni}(\mathrm{OH})_{2} / \mathrm{TiO}_{2}$ as the photocatalyst, separation of the particles was easy and there was no need to modify the $\mathrm{pH}$. 
The concentrations of 4-CP and SMX in the filtrates were determined by measuring the absorbance (at $\sim 246 \mathrm{~nm}$ and $266 \mathrm{~nm}$ respectively) at different irradiation times using a UV-Vis spectrophotometer (HP 8452-A diode array spectrophotometer).

FAs samples were analyzed by studying changes in fluorescence spectra using an excitation wavelength of $350 \mathrm{~nm}$. The efficiency of the photocatalysts was compared based on the physical adsorption of FAs on the surface and based on the disappearance of the fluorescent components of SRFA. No fluorescence detected after a certain irradiation time, does not mean complete degradation of SRFA or total mineralization. Longer irradiation times may be required to get the point of $>95 \%$ mineralization, but our experience with SRFA suggests that fluorescence is a good measure, which is sensitive to changes in composition as the mixture reacts. Fluorescence could also provide mechanistic insights if band are observed to shift [28]. A Varian Cary Eclipse fluorescence spectrophotometer was used. The slit-widths were adjusted at $5 \mathrm{~nm}$ for both excitation and emission and the photomultiplier was set to operate at 1000 volts. To study the effect of $\mathrm{O}_{2}$ concentration on the reaction, $\mathrm{O}_{2}$ was bubbled through the solutions during photocatalytic degradation.

\section{Conclusions}

This study was undertaken as a part of a program aimed at evaluation of the opportunities for photocatalytic water treatment created by the emergence of LED light sources. At visible wavelengths, LEDs are already the most efficient converters of electrical energy to light and progress into the UV is proceeding on a learning curve parallel to that of visible counterparts. If solar energy use is desirable, as in remote locations, DC operated LEDs can be powered from a photovoltaic array. In this study, we selected a cross-section of $\mathrm{TiO}_{2}$ compositions for investigations for superior performance as a candidate for application for water treatment. The main conclusion is that, of the photocatalysts investigated, none were outstandingly superior or totally inferior to Degussa $\mathrm{P} 25 \mathrm{TiO}_{2}$. This then leads us to conclude that the choice of a particular photocatalyst for a reactor will depend primarily on photoreactor design issues. Some candidates appear to require slurry use, whereas others are obvious candidates are best for fixed beds. At this stage, it is difficult to nominate a substitute for inexpensive, commercial Degussa P25 as a broad spectrum photocatalyst for such reactors.

\section{Appendix}

This Appendix includes a list of $\mathrm{TiO}_{2}$ photocatalysts reported in the literature, mostly rare earth doped, and their relative reactivities for specific model compounds compared to corresponding undoped catalysts and/or P25 (Table A1) and, Scanning Electron Microscopy with X-ray microanalysis SEM/EDS results for $\mathrm{WO}_{3} / \mathrm{TiO}_{2}$, Mesoporous $\mathrm{TiO}_{2}$ and Eu doped $\mathrm{TiO}_{2}$ (Figure A1). 
Table A1. Some of the synthesized photocatalysts reported in the literature, chosen model compounds for the reactivity test, light source and their relative reactivities compared to corresponding undoped catalysts and P25.

\begin{tabular}{|c|c|c|c|c|}
\hline Photocatalyst & Light source & Model compound & $\begin{array}{l}\text { Reactivity compared to } \\
\text { P25 or un-doped } \mathrm{TiO}_{2}\end{array}$ & Reference \\
\hline $\begin{array}{c}\mathrm{Sm}, \mathrm{N} \text { co-doped } \\
\mathrm{TiO}_{2} \\
\text { nanoparticles }\end{array}$ & $\begin{array}{c}\text { Tungsten lamp } \\
\text { with cut off filter } \\
420 \mathrm{~nm}\end{array}$ & Salycilic acid & Not reported & {$[37]$} \\
\hline $\begin{array}{l}\text { Lanthana-doped } \\
\text { mesoporous } \mathrm{TiO}_{2} \\
\text { nanoparticles }\end{array}$ & black lamps & Rhodamine B & Better than both & {$[38]$} \\
\hline $\begin{array}{l}\mathrm{Tb}, \mathrm{Eu} \text { and } \mathrm{Sm} \\
\text { doped } \mathrm{TiO}_{2} \\
\text { nanoparticles }\end{array}$ & Xenon arc lamp & Remazol Red RB-133 & Not reported & [39] \\
\hline $\mathrm{Eu}, \mathrm{Pr}, \mathrm{Yb}$ & Xe (Hg) lamp & $\begin{array}{l}\text { p-Nitrobenzoic acid, } \\
\text { p-chlorophenoxy } \\
\text { acetic acid, aniline, } \\
\text { salicylic acid and trans- } \\
\text { cinnamic acid }\end{array}$ & Not reported & {$[40]$} \\
\hline $\mathrm{Eu}, \mathrm{Pr}, \mathrm{Yb}$ & $\mathrm{Xe}(\mathrm{Hg})$ lamp & $\begin{array}{c}\text { Salicylic acid and } \\
\text { t-cinnamic acid }\end{array}$ & Not reported & [41] \\
\hline $\begin{array}{l}\mathrm{La}, \mathrm{Pr}, \mathrm{Nd}, \mathrm{Sm}, \\
\mathrm{Eu}, \mathrm{Gd}, \mathrm{Yb} \\
\text { doped } \mathrm{TiO}_{2}\end{array}$ & $\begin{array}{l}\text { medium pressure } \\
\text { mercury lamp }\end{array}$ & Rhodamine B & Not reported & {$[42]$} \\
\hline Sm doped $\mathrm{TiO}_{2}$ & $\begin{array}{l}\text { halogen tungsten } \\
\text { lamp with a UV } \\
\text { and IR cut-off } \\
\text { filter }\end{array}$ & Methylene Blue & Not reported & {$[43]$} \\
\hline $\begin{array}{l}\mathrm{Sm} \text { doped } \mathrm{TiO}_{2} \\
\mathrm{Sm}^{3+} \mathrm{Nd}^{3+} \mathrm{Ce}^{3+}\end{array}$ & sunlight & Methylene Blue & Better than both & {$[44]$} \\
\hline $\begin{array}{l}\left(\mathrm{Sm}^{2}, \mathrm{Ne}^{3}, \mathrm{Ce}\right. \\
\left.\text { and } \mathrm{Pr}^{3+}\right) \text { doped } \\
\text { titania-silica }\end{array}$ & sunlight & Methylene Blue & $\begin{array}{l}\text { Better than undoped } \\
\text { titania-silica }\end{array}$ & {$[45]$} \\
\hline $\begin{array}{c}\mathrm{Ce}, \mathrm{Co}, \mathrm{Eu}, \mathrm{Sm}, \\
\mathrm{W} \text { and } \mathrm{Yb} \text { doped } \\
\mathrm{TiO}_{2}\end{array}$ & $\begin{array}{c}\text { medium } \\
\text { pressure Hg lamp }\end{array}$ & 4-Nitrophenol & $\begin{array}{c}\text { Sm and } \mathrm{W} \text { doped } \mathrm{TiO}_{2}, \\
\text { better than } \mathrm{P} 25\end{array}$ & {$[46]$} \\
\hline $\mathrm{Eu}, \mathrm{N}$ & $\begin{array}{l}\text { Halogen lamp } \\
\text { with } 400 \mathrm{~nm} \text { cut } \\
\text { off filter }\end{array}$ & $\begin{array}{l}\text { Reactivebrilliant } \\
\text { red X-3B }\end{array}$ & $\begin{array}{l}\text { Better than both under } \\
\text { visible light irradiation }\end{array}$ & {$[22]$} \\
\hline $\begin{array}{l}\mathrm{La}, \mathrm{Ce}, \mathrm{Pr}, \mathrm{Nd}, \\
\mathrm{Sm}, \mathrm{Eu}, \mathrm{Dy}, \mathrm{Gd} \\
\text { doped } \mathrm{TiO}_{2}\end{array}$ & $\begin{array}{c}254,365 \text { and } 400 \\
\mathrm{~nm}\end{array}$ & Orange II dye & $\begin{array}{c}\text { Nd highest reactivity, } \\
\text { better than both at all } \\
\text { wavelengths for } \mathrm{Ce} \& \mathrm{Nd} \\
\text { doped } \mathrm{TiO} 2\end{array}$ & {$[32]$} \\
\hline $\begin{array}{l}\mathrm{La}, \mathrm{Nd} \text { and } \mathrm{Pr} \\
\text { doped } \mathrm{TiO}_{2}\end{array}$ & Solar irradiation & Methylene Blue & Better than undoped & {$[47]$} \\
\hline $\begin{array}{c}\mathrm{ABO}_{3} \text {-type :A) Y, } \\
\mathrm{La}, \mathrm{Nd}, \mathrm{Sm}, \mathrm{Eu}, \\
\mathrm{Gd}, \mathrm{Dy}, \mathrm{Yb} ; \mathrm{B}) \\
\mathrm{Al}, \mathrm{In}\end{array}$ & Xenon arc lamp & Toluene & Not reported & {$[48]$} \\
\hline
\end{tabular}


Figure A1. Scanning electron microscopy with X-ray microanalysis SEM/EDS was performed using a LEO 1530 (SEM images were taken with previous gold-coating) for: (A) $\mathrm{WO}_{3} / \mathrm{TiO}_{2} ;$ (B) Mesoporous $\mathrm{TiO}_{2} ;$ (C) Eu doped $\mathrm{TiO}_{2}$.
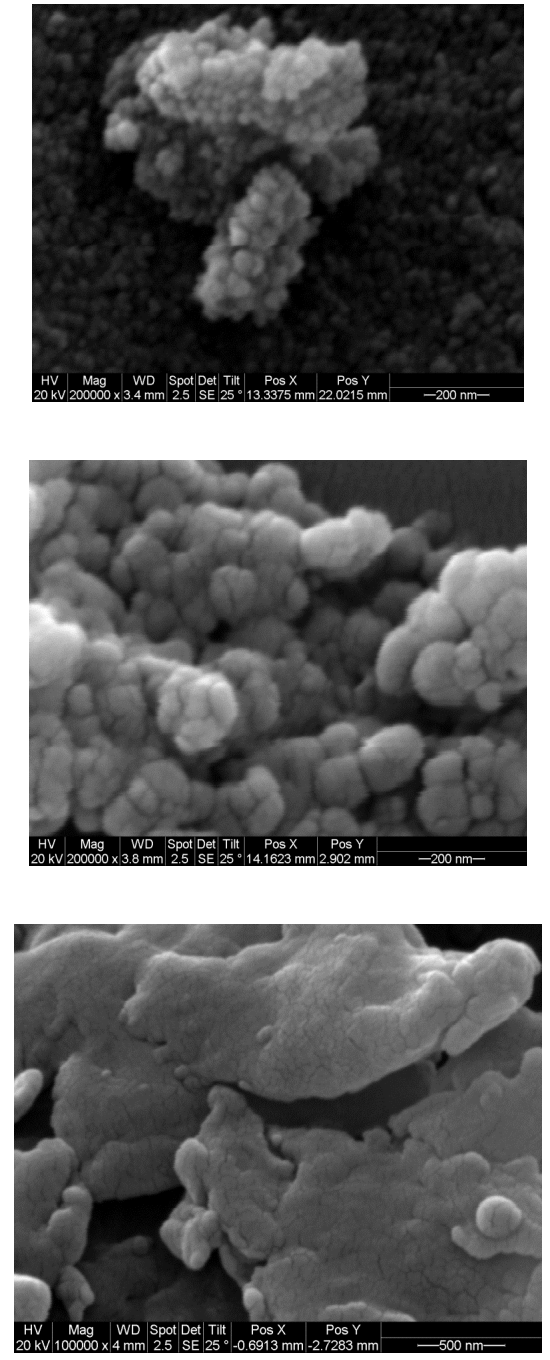

\begin{tabular}{|c|c|c|c|c|}
\hline Elem & Wt $\%$ At $\%$ K-Ratio & Z & A & $\mathrm{F}$ \\
\hline $\mathrm{OK}$ & 27.9057 .980 .0345 & 1.1308 & 0.109 & 51.0000 \\
\hline TiK & 56.4439 .190 .5247 & 0.9669 & 0.9587 & 71.0029 \\
\hline W L & $\begin{array}{lll}15.66 & 2.83 & 0.1186\end{array}$ & 0.7490 & 1.0113 & 31.0000 \\
\hline
\end{tabular}

(A)

\begin{tabular}{|c|c|c|c|c|c|c|}
\hline Elem & wt $\%$ & At $\%$ & K-Ratio & Z & A & $\mathrm{F}$ \\
\hline 0 & 35.7 & 62.21 & 0.0415 & 1.0975 & 0.1057 & 1.00 \\
\hline 5 & 1.09 & 1.08 & 0.0073 & 1.0510 & 0.6351 & 1.0045 \\
\hline & 63.16 & 36.71 & 0.5950 & 0.9353 & 1.0073 & 1.0000 \\
\hline
\end{tabular}

(B)

(C)

Other samples:

- $\mathrm{Ni}(\mathrm{OH})_{2}$ coated on $\mathrm{P}-25$;

- Nanofibre $\mathrm{TiO}_{2}$ was supplied by the authors of reference [12]. Full characterization is found there.

Figure A2. Top view of $365 \mathrm{~nm}$ LED rector: (a) lights on (b) lights off, Adapted from reference [35].

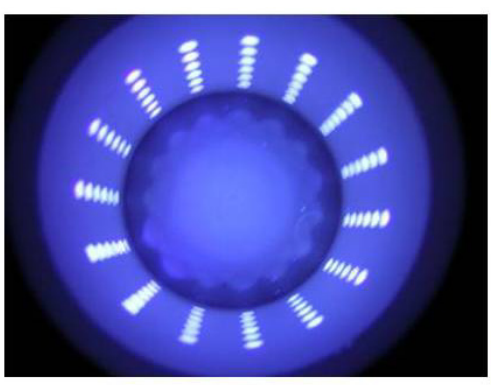

(a)

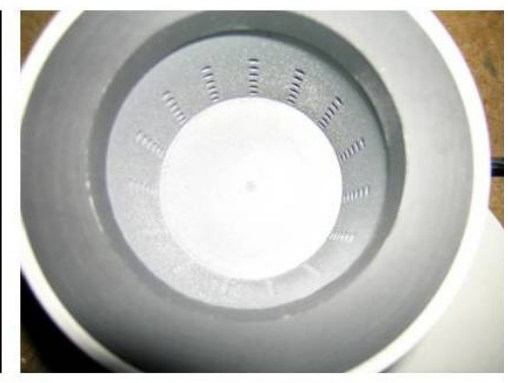

(b) 


\section{Acknowledgements}

We gratefully acknowledge the financial support of NSERC through RES'EAU WaterNet.

\section{Conflicts of Interest}

The authors declare no conflict of interest.

\section{References}

1. Parsons, S. Advanced Oxidation Processes for Water and Waste Water Treatment; IWA: London, UK, 2004.

2. Comninellis, C.; Kapalka, A.; Malato, S.; Parsons, S.A.; Poulios, I.; Mantzavinos, D. Perspective advanced oxidation processes for water treatment: advances and trends for R\&D. J. Chem. Technol. Biotechnol. 2008, 83, 769-776.

3. Tayade, R.J.; Natarajan, T.S.; Bajaj, H.C. Photocatalytic degradation of methylene blue dye using ultraviolet light emitting diodes. Ind. Eng. Chem. Res. 2009, 48, 10262-10267.

4. Natarajan, T.S.; Thomas, M.; Natarajan, K.; Bajaj, H.C.; Tayade, R.J. Study on UV-LED/TiO2 process for degradation of Rhodamine B dye. Chem. Eng. J. 2011, 169, 126-113.

5. Natarajan, T.S.; Natarajan, K.; Bajaj, H.C.; Tayade, R.J. Energy efficient UV-LED source and $\mathrm{TiO}_{2}$ nanotube array-based reactor for photocatalytic application. Ind. Eng. Chem. Res. 2011, 50, $7753-7762$.

6. Dai, K.; Lu, L.; Dawson, G. Development of UV-LED/TiO 2 device and their application for photocatalytic degradation of methylene blue. J. Mater. Eng. Perform. 2013, 22, 1035-1040.

7. Jo, W.K. Photocatalytic oxidation of low-level airborne 2-propanol and trichloroethylene over titania irradiated with bulb-type light-emitting diodes. Materials 2013, 6, 265-278.

8. Wang, Z.; Liu, J.; Dai, Y.; Dong, W.; Zhang, S.; Chen, J. CFD modeling of a UV-LED photocatalytic odor abatement process in a continuous reactor. J. Hazard. Mater. 2012, 215-216, $25-31$.

9. Jo, W.K.; Eun, S.S.; Shin, S.H. Feasibility of light-emitting diode uses for annular reactor inner-coated with $\mathrm{TiO}_{2}$ or nitrogen-doped $\mathrm{TiO}_{2}$ for control of dimethyl sulfide (Degussa P25). Photochem. Photobiol. 2011, 87, 1016-1023.

10. Sharmin, R.; Ray, M.B. Application of ultraviolet light-emitting diode photocatalysis to remove volatile organic compounds from indoor air. J. Air Waste Manag. Assoc. 2012, 62, 1032-1039.

11. Ghosh, J.P.; Langford, C.H.; Achari, G. Characterization of an LED based photoreactor to degrade 4-Chlorophenol in an aqueous medium using coumarin (C-343) sensitized $\mathrm{TiO}_{2}$. J. Phys. Chem. A 2008, 112, 10310-10314.

12. Ghosh, J.P.; Sui, R.; Langford, C.H.; Achari, G.; Berlinguette, C.P. A comparison of several nanoscale photocatalysts in the degradation of a common pollutant using LEDs and conventional UV light. Water Res. 2009, 4 3, 4499-4506.

13. Chong, M.N.; Jin, B.; Chow, W.K.; Saint, C. Recent development in photocatalytic water treatment technology: A review. Water Res. 2010, 44, 2997-3027. 
14. Byrne, J.A.; Fernandez-Ibañez, P.A.; Dunlop, P.S.M.; Alrousan, D.M.A.; Hamilton, J.W.J. Photocatalytic enhancement for solar disinfection of Water: A Review. Int. J. Photoenergy 2011, 798051:1-798051:12.

15. Ohtani, B. Photocatalysis A to Z- what we know and what we do not know in a scientific sense. J. Photochem. Photobiol. C 2012, 12, 157-178.

16. Hurum, D.C.; Agrios, A.G.; Gray, K.A. Explaining the enhanced photocatalytic activity of Degussa P25 mixed.phase $\mathrm{TiO}_{2}$ using EPR. J. Phys. Chem. B 2003, 107, 4545-4549.

17. Yu, J.; Hai, Y.; Cheng, B. Enhanced photocatalytic $\mathrm{H}_{2}$-production activity of $\mathrm{TiO}_{2}$ by $\mathrm{Ni}(\mathrm{OH})_{2}$ cluster modification. J. Phys. Chem. C 2011, 115, 4953-4958.

18. Zhao, D.; Chen, C.; Yu, C.; Ma, W.; Zhao, J. Photoinduced electron storage in $\mathrm{WO}_{3} / \mathrm{TiO}_{2}$ nano hybride material in the presence of oxygen and post irradiated reduction of heavy metal ions. J. Phys. Chem. C 2009, 113, 13160-13165.

19. Pichat, P. Photocatalysis and Water Purification. From Fundamentals to Recent Applications; Wiley-VCH: Weinheim, Germany, 2013.

20. Sui, R.; Thangadurai, V.; Berlinguette, C.P. Simple protocol for generating $\mathrm{TiO}_{2}$ nanofibers in organic media. Chem. Mater. 2008, 20, 7022-7030.

21. Calleja, G.; Serrano, D.; Sanz, R.; Pizarro, P.; García, A. Study on the synthesis of high-surface-area mesoporous $\mathrm{TiO}_{2}$ in the presence of nonionic surfactants. Ind. Eng. Chem. Res. 2004, 43, 24852492.

22. Xu, J.; Ao, Y.; Yuana, D.C. A simple route for the preparation of Eu, N-codoped $\mathrm{TiO}_{2}$ nanoparticles with enhanced visible light-induced photocatalytic activity. J. Colloid Interf. Sci. 2008, 328, 447-451.

23. Lee, K.; Kim, D.; Roy, P.; Paramasivam, I.; Birajdar, B.I.; Spiecker, E.; Schmuli, P. Anodic formation of thick anatase $\mathrm{TiO}_{2}$ mesospounge layers for high efficiency photocatalysis. J. Am. Chem. Soc. 2010, 132, 1478-1479.

24. Sedach, P.A.; Gordon, T.J.; Sayed, S.Y.; Furstenhaupt, T.; Sui, R.; Baumgartner, T.; Berlinguette, C.P. Solution growth of anatase $\mathrm{TiO}_{2}$ nanowires from transparent conducting glass substrates. J. Mater. Chem. 2010, 20, 5063-5069.

25. Pelaez, M.; Nolan, N.T.; Pillai, S.C.; Seery, M.K.; Falaras, P.; Kontos, A.G.; Dunlop, P.S.M.; Hamilton, J.W.J.; Byrne, J.A.; O’Shea, K.; et al. A review on the visible light active titanium dioxide photocatalysts for environmental applications. Appl. Catal. B 2012, 125, 331-349.

26. Mccullagh, C.; Robertson, J.M.C.; Bahnemann, D.W.; Robertson, P.K.J. The application of $\mathrm{TiO}_{2}$ photocatalysis for disinfection of water contaminated with pathogenic micro-organisms: A review. Res. Chem. Intermediat. 2007, 33, 359-375.

27. Ryu, J.; Choi, Y.W. Substrate specific photocatalytic activities of $\mathrm{TiO}_{2}$ and multi-reactivity test for water treatment application. Environ. Sci. Technol. 2008, 42, 294-300.

28. Chamoli, U.; Achari, G.; Langford, C.H. Self-sensitized degradation of Natural Organic Matter (NOM) using $\mathrm{TiO}_{2}$ photocatalysis with visible light. Water Res., submitted for publication, 2013.

29. Chamoli, U.; Izadifard, M.; Achari, G.; Langford, C.H. Coliform inhibition by Natural Organic Matter (NOM) sensitized photocatalysis under visible light. J. Water Health., submitted for publication, 2013. 
30. Shah, S.I.; Li, W.; Huang, C.P.; Jung, O.N.C. Study of $\mathrm{Nd}^{3+}, \mathrm{Pd}^{2+}, \mathrm{Pt}^{4+}$ and $\mathrm{Fe}^{3+}$ dopant effect on photoreactivity of $\mathrm{TiO}_{2}$ nanoparticles. Proc. Natl. Acad. Sci. USA 2002, 99, 6482-6486.

31. Xiong, Z.; Xu, Y. Photosensitized oxidation of substituted phenols on aluminum phthalocyanine intercalated organoclay. Environ. Sci. Technol. 2005, 39, 651-657.

32. Stengl, V.; Bakardjiev, S.; Murafa, N. Preparation of photocatalytic activity of rare earth doped $\mathrm{TiO}_{2}$ nanoparticles. Mater. Chem. Phys. 2009, 114, 217-226.

33. Barakat, M.A.; Schaeffer, H.; Hayes, G.; Ismat-Shah, S. Photocatalytic degradation of 2-chlorophenol by Co-doped $\mathrm{TiO}_{2}$ nanoparticles. Appl. Catal. B 2004, 57, 23-30.

34. Hirsch, R.; Ternes, T.A.; Haberer, K.; Mehlich, A.; Ballwanz, F.; Kratz, K.L. Determination of antibiotics in different water compartments via liquid chromatography-Electrospray tandem mass spectrometry. J. Chromatogr. A 1998, 815, 213-223.

35. Yu, L.; Achari, G.; Langford, C.H. Photocatalytic degradation of 2,4-D with a LED based photoreactor. In Proceedings of 12th International Environmental Specialty Conference, Edmonton, Canada, 12-16 March 2012.

36. Hatchard, C.; Parker, C.A. A new sensitive chemical actinometer. II. potassium ferrioxalate as a standard chemical actinometer. Proc. R. Soc. Lond. A 1956, 235, 518-536.

37. Ma, Y.; Zhang, J.; Tian, B.; Chen, F.; Wang, L. Synthesis and characterization of thermally stable $\mathrm{Sm}, \mathrm{N}$ co-doped $\mathrm{TiO}_{2}$ with highly visible light activity. J. Hazard. Mater. 2010, 182, 386-393.

38. Peng, T.; Zhao, D.; Song, H.; Yan, C. Preparation of lanthana-doped titania nanoparticles with anatase mesoporous walls and high photocatalytic activity. J. Mol. Catal. A 2005, 236, 119-126.

39. Saif, M.; Abdel-Mottaleb, M.S.A. Titanium dioxide nanomaterial doped with trivalent lanthanide ions of $\mathrm{Tb}, \mathrm{Eu}$ and $\mathrm{Sm}$ : Preparation, characterization and potential applications. Inorg. Chem. Acta 2007, 360, 2863-2874.

40. Ranjit, K.T.; Cohen, H.; Willner, I.; Bossmann, S.; Braun, A.M. Lanthanide oxide-doped titanium dioxide: Effective photocatalysts for the degradation of organic pollutants. J. Mater. Sci. 1999, 34, 5273-5280.

41. Ranjit, K.T.; Willner, I.; Bossmann, S.H.; Braun, A.M. Lanthanide oxide doped titanium dioxide photocatalysts: Effective photocatalysts for the enhanced degradation of salicylic acid and t-cinnamic acid. J. Catal. 2001, 204, 305-313.

42. Quan, X.; Zhao, Q.; Tan, H.; Sang, X.; Wang, F.; Dai, Y. Comparative study of lanthanide oxide doped titanium dioxide photocatalysts prepared by co-precipitation and sol-gel process. Mater. Sci. Phys. 2009, 114, 90-98.

43. Xiao, Q.; Si, Z.; Yu, Z.; Qiu, G. Sol-gel auto-combustion synthesis of samarium-doped $\mathrm{TiO}_{2}$ nanoparticles and their photocatalytic activity under visible light irradiation. Mater. Sci. Eng. B 2007, 137, 189-194.

44. Thomas, J.; Kumar, K.P.; Mathew, S. Hydrothermal synthesis of samarium doped nanotitania as highly efficient solar photocatalyst. Sci. Adv. Mater. 2012, 2, 481-488.

45. Zhu, J.; Xie, J.; Chen, M., Jiang, D.; Wu, D. Temperature synthesis of anatase rare earth doped titania-silica photocatalyst and its photocatalytic activity under solar-light. Colloids Surf. A 2010, $355,178-182$.

46. Bellardita, M.; Addamo, M.; di Paola, A.; Palmisano, L. Photocatalytic behavior of metal-loaded $\mathrm{TiO}_{2}$ aqueous dispersions and films. Chem. Phys. 2007, 339, 94-103. 
47. Parida, K.M.; Sahu, N. Visible light induced photocatalytic activity of rare earth titania nanocomposites. J. Mol. Catal. A 2008, 287, 151-158.

48. Ding, J.; Bao, J.; Sun, S.; Luo, Z.; Gao, C. Combinatorial discovery of visible-light driven photocatalysts based on the $\mathrm{ABO}_{3}$-type $(\mathrm{A}=\mathrm{Y}, \mathrm{La}, \mathrm{Nd}, \mathrm{Sm}, \mathrm{Eu}, \mathrm{Gd}, \mathrm{Dy}, \mathrm{Yb}, \mathrm{B}=\mathrm{Al}$ and In) Binary Oxides. J. Comb. Chem. 2009, 11, 523-526.

(C) 2013 by the authors; licensee MDPI, Basel, Switzerland. This article is an open access article distributed under the terms and conditions of the Creative Commons Attribution license (http://creativecommons.org/licenses/by/3.0/). 